\title{
Frontières
}

\section{Un rituel de deuil dans le monde religieux}

\section{Patricia Saint-Cyr}

Volume 18, numéro 1, automne 2005

Hélas, célébrer la mort!

URI : https://id.erudit.org/iderudit/1074316ar

DOI : https://doi.org/10.7202/1074316ar

Aller au sommaire du numéro

Éditeur(s)

Université du Québec à Montréal

ISSN

1180-3479 (imprimé)

1916-0976 (numérique)

Découvrir la revue

Citer ce document

Saint-Cyr, P. (2005). Un rituel de deuil dans le monde religieux. Frontières, 18(1), 57-58. https://doi.org/10.7202/1074316ar d'utilisation que vous pouvez consulter en ligne.

https://apropos.erudit.org/fr/usagers/politique-dutilisation/ 


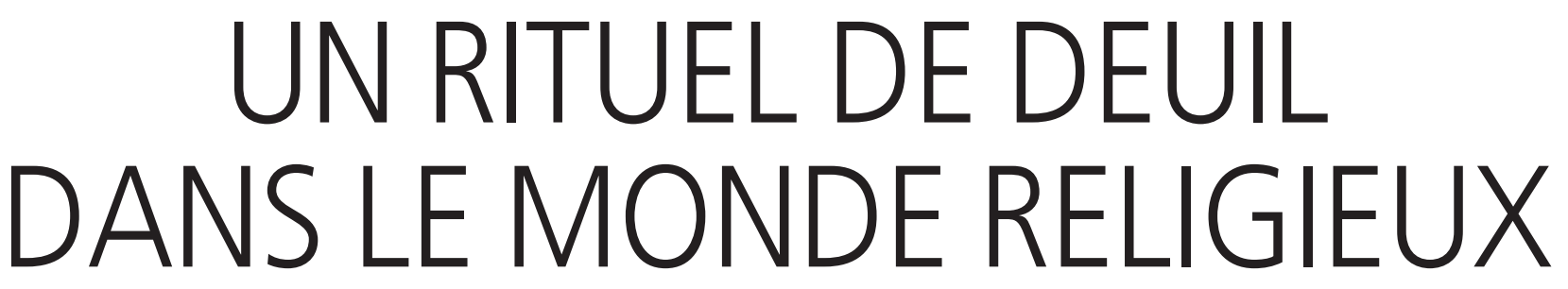

\author{
Patricia Saint-Cyr, \\ franciscaine missionnaire de Marie.
}

La société occidentale postmoderne aurait-elle perdu le sens du deuil? La multiplicité des livres, sessions et cours qui développent le sujet pourrait le laisser croire: le vide creuse un espace au besoin. Le problème vient peut-être aussi qu'on en parle beaucoup sans savoir comment le vivre. Pour assumer la douleur de la séparation d'une personne aimée et vivre une véritable catharsis, il faut du temps et de la profondeur. «Je ne connais de vie intérieure possible sans la patience du temps et du mûrissement»(Grand'Maison, 2004). Or tout le monde est pressé aujourd'hui. Agir immédiatement et vite, c'est la consigne de l'efficacité. Le temps à passer auprès de la personne disparue est tellement réduit et superficiel qu'il n'en reste à peu près rien. De lieux de recueillement qu'ils étaient, les salons funéraires deviennent des endroits où l'on parle de tout et de rien, mais peu de celui ou celle qui vient de partir vers l'ailleurs. Que reste-t-il de la «veillée au mort» à laquelle nos coutumes ancestrales consacraient temps, mémoire et compassion?

La vie est tissée de rencontres et de séparations, de gains et de pertes, de naissances et de morts. Au long des siècles, l'être humain doué de sagesse naturelle a inventé des rites, ou les a reçus de la tradition pour s'aider à intégrer les passages et en faire des lieux de croissance, d'enrichissement, de célébration. «La vérité de l'homme, c'est qu'il a autant besoin de rites, de coutumes et de traditions que de l'air qu'il respire. Pourquoi? Pour connaître le prix du bonheur, donner un sens à ses actes et à sa vie, pour être et pour devenir» (Meunier, 2003).

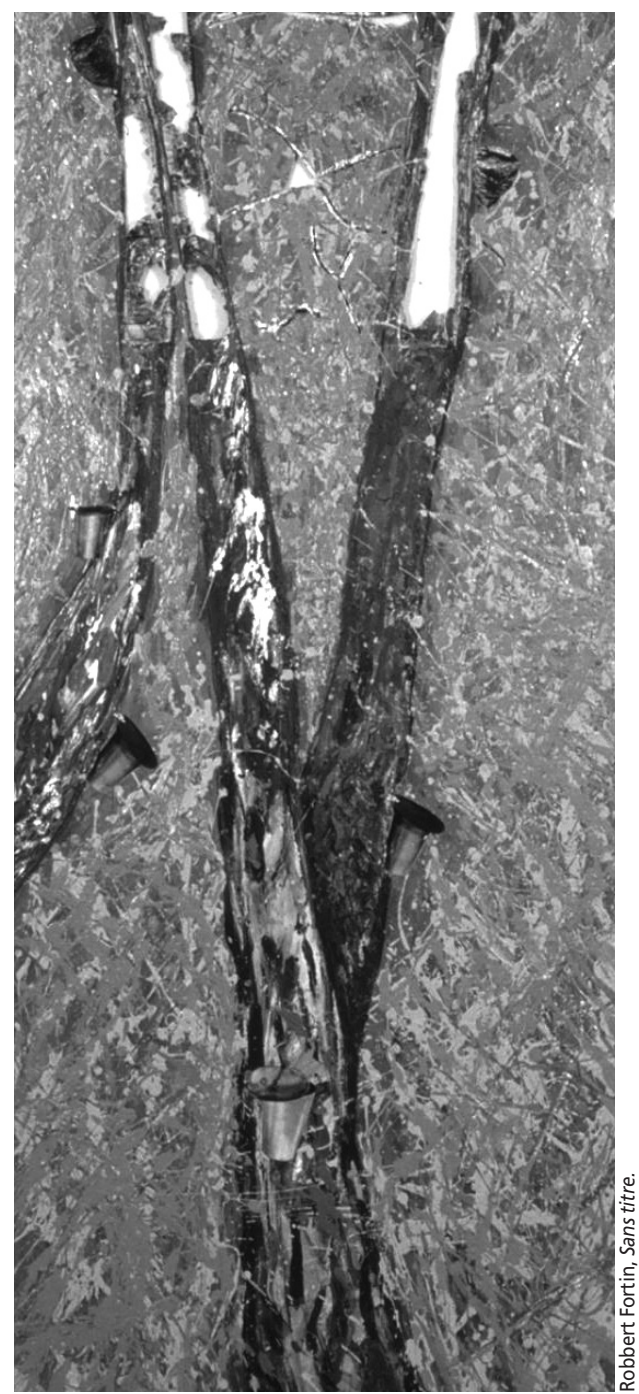

TOUT EST DANS LE CEUR

DE CELUI OU CELLE

QUI CÉLÈBRE.
À tort, on reproche aux rites d'être des coutumes routinières, alors qu'ils ont été inventés pour célébrer la nouveauté de chaque événement. On pourrait bien leur appliquer ce que Jean XXIII disait des traditions: «Je les aime tellement, que je voudrais en créer des nouvelles!» Tout est dans le cœur de celui ou celle qui célèbre.

Par sa composition et son organisation, la vie communautaire se prête aux traditions. Les rituels rythment les moments importants de la vie du groupe et permettent à ses membres de "créer un espace et un temps de gratuité afin de se retrouver, d'accueillir un événement qui leur tient à cœur et célébrer un sens particulier, le leur», comme l'exprime si bien Paul Meunier (2203). En fait, les communautés religieuses sont d'abord des lieux pleinement humains. Une vision commune fondée sur la foi et sur un système de valeurs transcendantes rassemble des personnes autour d'un projet de vie. Dans le groupe, chaque membre apporte sa personnalité, son unicité. Il en fait partie intégrante et y a toute sa place. Au fil du temps, des relations interpersonnelles et communautaires se tissent et s'enracinent: le sens d'appartenance les développe et permet de dépasser les différences. L'estime réciproque s'exprime davantage dans les gestes et les actes que dans les paroles élogieuses.

En communauté comme dans la société, la maladie est un temps qui privilégie l'expression de la solidarité, de la compassion et de la tendresse. La sœur visitée est réconfortée dans sa solitude et son inactivité. Et quand viennent les derniers moments, l'accompagnement prend la forme d'un rituel qui correspond autant que possible à 
la personnalité et au goût de la mourante. Silence et parole, prières et chants alternent; ils remémorent les grands moments d'une vie accomplie: jeunesse familiale, profession religieuse, expérience missionnaire. «Lorsque je serai sur mon lit de mort, j'aimerais que vous me chantiez: Je suis le Dieu des grands espaces et des vastes horizons", me disait une compagne dont une grande partie de la vie s'était passée à sillonner de nombreuses routes dans le monde. L'univers était devenu sa patrie et elle l'exprimait à sa façon. Dans une telle ambiance, le grand passage se vit dans la sérénité, la confiance et l'abandon.

Mais s'il est un temps où le rituel prend un sens et de l'importance, c'est bien celui de la mort. On y trouve un espace, un lieu, une parole qui permettent aux personnes éprouvées par la perte d'un parent ou d'un ami d'aller au bout de leur chagrin, de libérer leurs émotions, de vivre consciemment leur deuil. Un tel rituel, toutes les cultures en ont un qui leur est propre. Ne devraiton pas le réinventer dans l'aujourd'hui de chaque époque et de chaque société?

Les communautés religieuses ont aussi leurs traditions dans la façon de rendre hommage à leurs membres disparus. Même si de l'extérieur, ces institutions semblent mises à part et protégées par leur cloître, elles n'en sont pas moins tributaires de leur milieu et de leur époque. Avant le concile Vatican II, notre communauté, comme la plupart des familles du Québec, exposait pendant deux ou trois jours les sœurs qui venaient de partir pour un monde meilleur, comme cela se disait. Dans la salle du parloir, ouverte à la famille et aux proches, le corps de la défunte était déposé sur ce qu'on appelait «les planches»; c'était plutôt une table recouverte de tissu blanc que fleurissaient de blancs lis. Une présence priante et affectueuse était assurée jour et nuit, ponctuée de prières traditionnelles comme la récitation du chapelet. On se parlait à voix basse de ce que la sœur défunte avait été pour ceux et celles qui l'avaient connue, de ce qu'elle avait apporté à la mission. L'affection fraternelle s'exprimait de bouche à oreille, sans témoignage public cependant. La discrétion était plutôt de mise.

La veille des funérailles, le corps qui avait été déposé dans un cercueil étroit, blanc ou gris, était apporté à la chapelle de la communauté; les sœurs psalmodiaient en latin l'office des défunts, toujours le même. Le lendemain, la messe était celle qu'on célébrait dans toutes les églises en pareilles circonstances: le prêtre, revêtu des habits noirs de deuil, suivait littéralement le rituel décrit au lectionnaire, après quoi, en silence, le cercueil était escorté par toute la communauté jusqu'au cimetière placé, bien souvent, dans l'enceinte du couvent.
$\mathrm{Si}$, dans le passé, les rites étaient un peu figés par l'uniformité et la stabilité des structures, ils ont évolué depuis le renouvellement des règles de l'Église, tout comme d'ailleurs les us et coutumes de chaque congrégation. Progressivement, ils se sont personnalisés et adaptés aux circonstances et aux milieux. Cependant, le but reste le même: permettre à ceux qui les vivent «de se relier à des gens ayant vécu à des époques antérieures, de perpétuer un sens commun ou ancestral»(Meunier, 2003).

\section{À TORT,}

ON REPROCHE AUX RITES D'ÊTRE DES COUTUMES $\underline{\text { ROUTINIÈRES, }}$ ALORS QU'ILS ONT ÉTÉ INVENTÉS POUR CÉLÉBRER LA NOUVEAUTÉ DE CHAQUE ÉVÉNEMENT.

Ce qui a changé, c'est la forme, la manière. Pour fixer les funérailles, la famille est consultée. La veille de la cérémonie, le corps de la sœur revêtu d'une tenue simple, préparée par elle-même la plupart du temps, est exposé dans un cercueil sobre et modeste à l'image de sa vie. Dès lors, la prière et l'affection rassemblent la communauté et la famille autour de celle qui vient de les quitter et qu'elles peuvent revoir une dernière fois. Hymnes, psaumes et Parole de Dieu sont choisis avec soin, s'accordant à la vie de la sœur ou à ses dernières volontés si celles-ci se sont exprimées.

Cependant, la parole humaine y trouve aussi largement sa place. C'est un temps fort pour faire mémoire. Avec liberté et spontanéité, les sœurs ou les membres de la famille témoignent de leur attachement à celle qu'ils ont connue et aimée. Que ce soit dans la grande salle pendant la célébration de la veillée ou à la chapelle lors de l'Eucharistie, les souvenirs qui font surface rappellent ce que la sœur avait d'unique, ce qu'elle a été pour la famille et pour la communauté. «Du bord de la mort, on ne mesure pas la vanité de la vie et de notre humanité, mais leur grandeur, leur beauté, leur gravité»(Grand'Maison, 2004). Les souvenirs s'inspirent aussi des gestes et des écrits de la disparue. Par exemple, l'autobiographie d'Anne-Marie, décédée à 97 ans, dévoilait la vérité d'une personne dont le parcours ressemblait à un long pèlerinage marqué par de nombreux détachements qui avaient eu pour résultat d'alléger sa marche.
Le texte court, simple, humble laissait deviner une grandeur d'âme qui, par modestie, avait gardé silence «sur son jardin secret» (Grand'Maison, 2004). Ses notes étaient d'une telle limpidité qu'elles ont servi à formuler les intentions de la prière universelle lors de l'Eucharistie. En retraçant sa vie, elles embrassaient le monde. De tels témoignages nous apprennent le «prix du bonheur », c'est-à-dire celui d'avoir connu une personne qui a apporté quelque chose de neuf dans notre vie.

Les funérailles ont lieu à la chapelle de la communauté. Les sœurs y partagent leurs places avec la famille. Après la cérémonie, le corps est transporté au cimetière de la ville où plusieurs de ses consœurs l'ont devancée. L'accompagnent ceux et celles qui le désirent et qui le peuvent. Au Repos Saint-François d'Assise, une grande croix de granit rose, donnée par une famille, couvre de son ombre les tombes de près d'une centaine de sœurs dont les noms, pour ne pas s'effacer, sont gravés sur deux plaques de pierre. Ces noms, on les retrouve aussi près de la chapelle de la communauté, inscrits dans le grand livre, le nécrologe, dont la page ouverte à la date du jour, rappelle celles qui sont décédées chaque année ce même jour.

Le deuil ainsi vécu aide à retrouver les traces des chemins parcourus par ceux et celles qui ont fait le passage (Grand'Maison, 2004); il apprend aussi à mettre en relief ce que l'on veut garder par rapport à l'essentiel. Toute séparation creuse un vide, mais quand celui-ci se laisse habiter par le souvenir, un souvenir dont le rite dévoile la beauté et la richesse, alors on comprend le «prix du bonheur» dont parle le Petit Prince de Saint-Exupéry. Dans une société de l'éphémère comme la nôtre «où tout se joue à court terme», comme dit Jacques Grand'Maison, est-il possible de reconquérir le temps? Dans sa simplicité, le rituel en est un moyen privilégié. Mettant en valeur l'amitié, la tendresse et un peu de bonté partagée, il permet de redécouvrir le sens des choses et de retrouver sa tranquillité d'âme.

\section{Bibliographie}

MEUNIER, Paul (2003). La philosophie du Petit Prince ou le retour à l'essentiel, Montréal, Carte Blanche, 294 p.

GRAND'MAISON, Jacques (2004). Du jardin aux appels de la vie, ou Réconcilier l'intériorité et l'engagement, Montréal, Fides, $360 \mathrm{p}$. 